\title{
Epidemiology of pre invasive and invasive lesions of the cervix at tertiary health centre in Punjab
}

\author{
Garima Bhardwaj ${ }^{1 *}$, Amritpal Kaur ${ }^{1}$, Permeet Kaur Bagga ${ }^{2}$
}

\begin{abstract}
${ }^{1}$ Department of Obstetrics and Gynaecology, Government Medical College, Amritsar, Punjab, India
${ }^{2}$ Department of Pathology, Government Medical College, Amritsar, Punjab, India
\end{abstract}

Received: 26 January 2021

Revised: 28 February 2021

Accepted: 01 March 2021

\author{
*Correspondence: \\ Dr. Garima Bhardwaj, \\ E-mail: garimabrdj@gmail.com
}

Copyright: (C) the author(s), publisher and licensee Medip Academy. This is an open-access article distributed under the terms of the Creative Commons Attribution Non-Commercial License, which permits unrestricted non-commercial use, distribution, and reproduction in any medium, provided the original work is properly cited.

\begin{abstract}
Background: Cervical cancer is the fourth most frequent cancer in women globally, next to breast, colorectal and lung cancer and it is also the fourth most common cause of cancer death in women. According to the Indian council of medical research (ICMR), in India one woman dies of cervical cancer every 9 minutes. This study used PAP smear and histopathology to find out about the epidemiology of pre invasive and invasive lesions of the cervix at tertiary health centre in Punjab and their correlation with various social and demographic features.

Methods: This prospective clinical study was carried out in the Department of Obstetrics and Gynaecology in Amritsar Medical College from May 2018 to April 2020, after taking approval from the Institutional Ethical Committee. The study selected 500 women randomly among the patients attending the Gynaecology OPD who met the inclusion criteria. Detailed history and PAP smear was taken at first visit followed by cervical biopsy amongst women with abnormal cytology report or with frank lesions of cervix.

Results: Out of 500 women included in the study, majority of women $(82.5 \%)$ were Negative for intraepithelial lesion or malignancy (NILM), 4\% women had Atypical squamous cells of undetermined significance (ASCUS), $6.1 \%$ had low grade squamous intraepithelial lesion (LSIL) and 16 (3.2\%) had High grade squamous intraepithelial lesion (HSIL). Amongst the histopathology reporting $15.62 \%$ patients had cervical intraepithelial neoplasia 1 (CIN I), $6.25 \%$ patients had cervical intraepithelial neoplasia II (CIN II), 3.12\% patients had cervical intraepithelial neoplasia III (CIN III), $6.3 \%$ patients had squamous cell carcinoma and $3.1 \%$ patient had adenocarcinoma of cervix. Age, low level of education, poor socioeconomic status, early marriage and multiparity are the risk factors found to be associated with pre invasive and invasive lesions of the cervix. $(\mathrm{p}<0.001)$.

Conclusions: Though infection with human papilloma virus (HPV) is essential for the development of the disease, there are other high-risk factors like age, poor education, low socioeconomic status, early age at marriage and high parity which are significantly associated with the occurrence of the disease. Therefore, our primary and secondary preventive measures must include the women who come under these high-risk categories.
\end{abstract}

Keywords: Human papilloma virus, NILM, LSIL, HSIL, CIN, SCC

\section{INTRODUCTION}

Cervical cancer is a major cause of morbidity and mortality amongst women worldwide. It is the fourth most frequent cancer in women globally, next to breast, colorectal and lung cancer and it is also the fourth most common cause of cancer death in women. ${ }^{1}$ Cervical cancer ranks as the $2^{\text {nd }}$ leading cause of female cancer in India. According to ICMR, in India one women dies of cervical cancer every 9 minutes. ${ }^{2}$ Despite its high incidence, the knowledge and awareness among women regarding cervical cancer and its screening is limited. The 
highest incidence of cervical cancer was noted in Eswatini (Country in Southern Africa) where around $6.5 \%$ of women developed cervical cancer by the age of 75 years. $^{3}$ In the developed countries there is better coverage of screening programs and more access to human papilloma virus (HPV) vaccination. Better screening coverage leads to early treatment and prevents upto $80 \%$ of cervical cancers in developed countries. Globally, the crude incidence of cervical cancer is 15.1 per 1,00,000 women per year. ${ }^{4}$ Whereas in Southern Asia and India it is 12.7 and 14.9 per 1,00,000 women per year respectively. ${ }^{5}$

India has the second highest age standardized incidence rates amongst the south Asian countries. The age standardised rates of Nepal, India, Bhutan, Pakistan, Bangladesh, Sri Lanka are 21.5, 14.7, 14.4, 7.3, 10.6, 7.8 respectively. ${ }^{4,5}$ Cervical cancer is most frequently diagnosed between the age groups 35 and 44 years. 6 Average age at diagnosis of cancer cervix around the globe is 53 years ranging from 44 years at Vanuatu (a South Pacific Ocean nation) to 68 years at Singapore. ${ }^{7}$ The peak age at diagnosis in India is 55-59 years and considerable number of women are diagnosed during late stage of the disease. The cumulative risk percent at 75 years of age in India is $2 \%$ compared to $1 \%$ in southern Asia and world.

HPV infections acts as a key factor in the development of cervical cancer. ${ }^{8}$ HPV prevalence among cervical cancer patients varied from $87.8 \%$ to $96.67 \% .9$ The prevalence was found to be higher among high risk categories such as commercial sex workers $(25 \%)$, urban slums in Mumbai $(32.3 \%)$ and HIV positive women from $41.7 \%$ to $56 \%$. 9,10 The various predisposing risk factors implicated in causation of cancer cervix are Persistent HPV infection, early age at coitarche (<16 years), early child bearing ( $<20$ years), multiple sexual partners, multiparity with poor birth spacing, multiple sexual partners, malnutrition, low socioeconomic status, immunocompromised state, pre-existing sexually transmitted diseases, poor personal hygiene, previous history of dysplasia, oral contraceptives and progesterone use continuously over 8 years, in utero exposure to diethylstilbestrol, diet low in fruits and vegetables, smoking and drug abuse and family history of cervical cancer. $^{11-14}$

It has been established by various studies that screening by conventional Pap smear has reduced the mortality by $70 \% .{ }^{15}$ But the sensitivity of the procedure is $50-60 \%$ and may reach up to $80 \%$ at its best and so is associated with false negative rate of $20-50 \% .^{16}$ The Pap slides are interpreted according to the 2014 Bethesda system for reporting of cervical cytology.

\section{METHODS}

This prospective clinical study was carried out in the Department of Obstetrics and Gynaecology in Amritsar
Medical College from May 2018 to April 2020, after taking approval from the Institutional Ethical Committee. The study selected 500 women randomly among the patients attending the Gynaecology OPD who met the inclusion criteria.

Inclusion criteria included sexually active married female of age 20-65 years who had features of suspicious cervix on visual inspection lik erosion, chronic cervicitis, healed lacerations, hypertrophic cervix, bleeds on touch. Pregnant women, women who have used vaginal medications or contraception in the last 48 hours of examination and women who have undergone total hysterectomy were excluded from the study.

The following study was carried out in Bebe Nanki Mother and Child Care Hospital, Department of Obstetrics and Gynaecology, Govt. Medical College, Amritsar during the study period. 500 women were randomly selected amongst the women attending the gynaecology OPD. Procedure was explained and written informed consent was taken from all the patients included in the study. At the first visit, detailed history was taken and epidemiological profile of the patients was noted, then general examination, systemic examination and local examination was performed. And then PAP smear was taken at the squamocolumnar junction with the Ayer's spatula in clockwise direction for 360 degree. Smear was fixed in $95 \%$ ethanol or liquid based cytology sample was taken by a brush like device and the device was broken off into a vial of preservative fluid. Sample was transported to a pathology laboratory where debris such as mucus or blood was removed and a thin layer of cervical cells deposited on a microscope slide was stained with papanicolaou stain. Wedge biopsy was taken from cervix in cases of gross cervical lesions, abnormal cytological findings or from areas of frank lesion at the next visit. Biopsy sample was fixed in formalin solution and then sent to the pathology department for histopathological evaluation. Three patients had frank growth on cervix, so direct biopsy was taken in these patients bypassing the PAP smear test. The data was collected and analyzed systematically to study the epidemiology of cervical lesions among patients attending the tertiary care centre in Punjab. The statistical tool used to analyse data was SPSS version 23.0.

\section{RESULTS}

The study included 500 patients who fulfilled the inclusion criteria attending the gynaecology OPD at the BNMCC, GMC, Amritsar. Out of these 500 women, Pap smear was taken in 497 women and in 3 women direct biopsy was taken bypassing Pap smear as they had frank growth on per speculum examination. $66(13.3 \%)$ women were found to be positive (ASCUS, LSIL and HSIL) on cytology. Cervical biopsy was taken in 32 women, who were either positive on cytology reporting or had unhealthy cervix or frank growth on per speculum examination. 


\section{Cytology report}

Out of 500, Pap smear was taken in 497 women as 3 women had frank growth on per speculum examination, so direct biopsy was taken in those patients. $410(82.5 \%)$ women were reported as NILM on cytology, of which 21 $(4.2 \%)$ were reported as bacterial vaginosis and $4(0.8 \%)$ as atrophic. $21(4.2 \%)$ smears were reported as unsatisfactory and $66(13.3 \%)$ were reported as precancerous lesions. Of the precancerous lesions 20 (4.0\%) were reported as ASCUS, 30 (6.1\%) were reported as LSIL, $16(3.2 \%)$ were reported as HSIL on cytology. Most common cytological finding was NILM $(82.5 \%)$.

\section{Histopathology report}

Cervical biopsy was taken in 32 women, who were either positive on cytology reporting or had unhealthy cervix or frank growth on per speculum examination. Histopathology report was found to be Chronic cervicitis in $13(40.6 \%)$ women and normal in $8(25 \%)$. It was CIN I in $5(15.62 \%)$, CIN II in $2(6.25 \%)$ while CIN III in 1 $(3.12 \%)$ cases. Squamous cell carcinoma of cervix was found in $2(6.25 \%)$ and adenocarcinoma of cervix in 1 $(3.12 \%)$ patient.

The various risk factors found to be associated with pre invasive and invasive lesions of the cervix were studied in detail and are presented below:

\section{Age}

Out of 500 women 92 (18.4\%) were between the 21-30year age group, $203(40.6 \%)$ were between $31-40$ years age groups, $133(26.6 \%)$ belonged $41-50$ years, 51 (10.2\%) were between 51-60 years and $21(4.2 \%)$ were above 60 years. Out of 500 women, the majority (40.6\%) of women belonged to the 31-40-year age group. The mean age was 40.11 years. Maximum numbers of cases (36.4\%) with positive cytologic and histologic findings were in the age group of 31-40 years. A progressive increase was noted in the frequency of SIL (squamous intraepithelial lesions) with increasing age and this was found to be statistically significant $(\mathrm{p}<0.001)$. However, relationship between increasing age and positive histopathological findings was not established ( $\mathrm{p}$ value 0.109).

Table 1: Relationship between age group and cytological findings.

\begin{tabular}{|lllllll|}
\hline \multirow{2}{*}{ Age group (in years) } & \multicolumn{7}{c|}{ Cytological findings on pap smear } & Unsatisfactory & NILM & ASCUS & LSIL & HSIL \\
\hline \multirow{2}{*}{$\leq \mathbf{3 0}$} & $\mathrm{N}$ & 2 & 85 & 2 & 3 & 0 \\
\hline \multirow{2}{*}{$\mathbf{3 1 - 4 0}$} & $\%$ & 2.2 & 92.4 & 2.2 & 3.3 & 0.0 \\
\hline \multirow{2}{*}{$\mathbf{4 1 - 5 0}$} & $\mathrm{N}$ & 6 & 173 & 9 & 8 & 7 \\
& $\%$ & 3.0 & 85.3 & 4.4 & 3.9 & 3.4 \\
\hline \multirow{2}{*}{$\mathbf{5 1 - 6 0}$} & $\mathrm{N}$ & 10 & 100 & 6 & 12 & 3 \\
\hline \multirow{2}{*}{$>\mathbf{6 0}$} & $\%$ & 7.5 & 75.2 & 4.5 & 9.0 & 2.3 \\
& $\mathrm{~N}$ & 2 & 38 & 1 & 4 & 5 \\
\hline
\end{tabular}

Table 2: Relationship between education level and cytological findings $(n=497)$.

\begin{tabular}{|lllllll|}
\hline \multirow{2}{*}{ Variables } & \multicolumn{7}{c|}{ Cytological findings on PAP Smear } \\
Illiterate & $\mathrm{N}$ & NILM & Unsatisfactory & ASCUS & LSIL & HSIL \\
\cline { 2 - 7 } & $\%$ & 66 & 5 & 6 & 9 & 4 \\
\hline \multirow{2}{*}{ Up to primary } & $\mathrm{N}$ & 185 & 6.9 & 8.3 & 12.5 & 5.6 \\
\cline { 2 - 7 } & $\%$ & 82.6 & 3.1 & 4.9 & 6.7 & 2.7 \\
\hline \multirow{2}{*}{ Middle and higher secondary } & $\mathrm{N}$ & 133 & 9 & 3 & 4 & 6 \\
\hline \multirow{2}{*}{ More than higher secondary } & $\%$ & 85.8 & 5.8 & 1.9 & 2.6 & 3.9 \\
\hline \multirow{2}{*}{ Total } & $\mathrm{N}$ & 44 & 0 & 0 & 2 & 0 \\
\cline { 2 - 7 } & $\%$ & 95.7 & 0.0 & 0.0 & 4.3 & 0.0 \\
\hline & $\mathrm{N}$ & 410 & 21 & 20 & 30 & 16 \\
\cline { 2 - 7 } & $\%$ & 82.5 & 4.2 & 4.0 & 6.0 & 3.2 \\
\hline
\end{tabular}

$\mathrm{P}$ value $=0.003$ 
Table 3: Relationship between coitarche and cytological findings.

\begin{tabular}{|c|c|c|c|c|c|c|}
\hline \multirow{2}{*}{$\begin{array}{l}\text { Age at coitarche } \\
\text { (in years) }\end{array}$} & & \multicolumn{5}{|c|}{ Cytological findings on PAP smear } \\
\hline & & NILM & Unsatisfactory & ASCUS & LSIL & HSIL \\
\hline \multirow{2}{*}{$\leq \mathbf{2 0}$} & $\mathrm{N}$ & 150 & 7 & 10 & 22 & 16 \\
\hline & $\%$ & 73.2 & 3.4 & 4.9 & 10.7 & 7.8 \\
\hline \multirow{2}{*}{$>\mathbf{2 0}$} & $\mathrm{N}$ & 260 & 14 & 10 & 8 & 0 \\
\hline & $\%$ & 89.0 & 4.8 & 3.4 & 2.7 & 0.0 \\
\hline \multirow{2}{*}{ Total } & $\mathrm{N}$ & 410 & 15 & 20 & 30 & 16 \\
\hline & $\%$ & 82.5 & 3.1 & 4.1 & 6.1 & 3.3 \\
\hline
\end{tabular}

$\mathrm{P}$ value $<0.001$

\section{Residence}

Out of 500 patients included in the study, $219(43.8 \%)$ belonged to rural areas and $281(56.2 \%)$ belonged to urban areas. No clear association could be established between residential area and development of cervical lesions.

\section{Education}

Out of 500 women studied, $73(14.6 \%)$ women were illiterate, $226(45.2 \%)$ were educated up to primary level, $155(31.0 \%)$ up to middle and higher secondary level and only $46(9.2 \%)$ women were educated more than higher secondary level. Maximum women were educated up to primary level. Out of total 66 patients positive on cytology, majority $(77.3 \%)$ were either educated up to primary level or were illiterate. Similarly, $81.7 \%$ patients positive on histology were either educated up to primary level or were illiterate ( $\mathrm{p}$ value 0.03 ).

\section{Socioeconomic status}

Majority of women 249 (49.8\%) belonged to the lower class of modified Kuppuswamy scale. 154 (30.8\%) women belonged to upper lower, $80(16 \%)$ belonged to lower middle, $13(2.6 \%)$ were in upper middle class and 4 $(0.8 \%)$ were in upper class of modified Kuppuswamy scale. $77.3 \%$ of women with positive cytology and $72.7 \%$ of women with positive histopathology belonged to lower class of modified Kuppuswamy scale. Only one patient in upper middle class and none of the patients of the upper class were found to be positive on cytologic and histopathologic testing. This is probably because of better hygienic practices and more awareness of screening methods among the affluent classes.

\section{Age at coitarche}

Out of 500 women, $23(4.6 \%)$ women had coitarche at the age of less than 18, $185(37 \%)$ women at 18-20 years and $292(58.4 \%)$ women had coitarche at more than 20 years of age. $72.7 \%$ of women with positive cytology and $90.9 \%$ of women with positive cytology had coitarche before or at the age of 20 years. Early age at first sexual intercourse is associated with increased risk of high risk
HPV infection which is necessary for the development of cervical cancer $(\mathrm{p}<0.001)$.

\section{Parity}

Maximum $253(50.6 \%)$ were of parity 2, $109(21.8 \%)$ were of parity $3,63(12.6 \%)$ were of parity 1 and 19 (3.8\%) were nullipara. Others with parity 4 and above were $39(7.8 \%)$ and $17(3.4 \%)$ respectively. The mean parity was found to be 2.88 . In the present study it is found that pre invasive and invasive lesions of cervix are found more with increasing parity of more than or equal to 3 and this difference was found to be statistically significant $(\mathrm{p}<0.001)$. Out of the 19 nulliparous women, no one was found to have squamous intraepithelial lesion. SIL was found in $7.6 \%, 30.3 \%, 39.4 \%, 22.7 \%$ of women amongst parity one, two, three and more than three respectively. $81.8 \%$ of dysplasias or cancer cervix on histology and $62.1 \%$ of epithelial cellular changes on Pap smear occurred in women with parity more than or equal to 3 .

\section{Age at first pregnancy}

Out of 500 women, 19 were nulliparous, $116(23.86 \%)$ had their first pregnancy before the age of 20,352 (73.25\%) had first pregnancy between 21 to 30 years and $14(2.89 \%)$ had at the age of more than 30 . The mean age at first child birth noted in the study is 22.86 years. The relationship between the age at first pregnancy and the occurrence of epithelial cell lesions on cytology and dysplasias/ cancer cervix on histology is found to be significant $(\mathrm{p}<0.001) .57 .6 \%$ of women with positive cytology and $90.9 \%$ of women with positive histology had their first child birth at or before the age of 20 years.

\section{Chief complaints}

Total 141 (28.2\%) women had complaints of discharge per vaginum, $121(24.2 \%)$ had pain abdomen, 99 (19.8\%) had menstrual abnormalities, $37(7.4 \%)$ had come for regular checkup, 39 (7.8\%) complained of dysuria, 36 $(7.2 \%)$ had pruritis, $16(3.2 \%)$ had postmenopausal bleeding and $11(2.2 \%)$ complained of post coital bleeding. Most common complaints were discharge per vaginum and pain abdomen. The frequency of SIL in symptomatic women was found to be $13.60 \%$ as against to $2.70 \%$ in asymptomatic women and this difference was 
also found to be statistically significant $(\mathrm{p}<0.001)$. Symptom wise the frequency of SIL was maximum in women complaining of post coital bleeding (80\%), followed by postmenopausal bleeding (26.6\%), pruritis (19.4\%), menstrual abnormalities (15.3\%).

Table 4: Relationship between parity and cytological findings.

\begin{tabular}{|c|c|c|c|c|c|c|}
\hline \multirow{2}{*}{$\begin{array}{l}\text { Obstetri } \\
\text { formula }\end{array}$} & & \multicolumn{5}{|c|}{ Cytological findings on PAP smear } \\
\hline & & NILM & Unsatisfactory & ASCUS & LSIL & HSIL \\
\hline \multirow{2}{*}{ P0 } & $\mathrm{N}$ & 19 & 0 & 0 & 0 & 0 \\
\hline & $\%$ & 100.0 & 0.0 & 0.0 & 0.0 & 0.0 \\
\hline \multirow{2}{*}{ P1 } & $\mathrm{N}$ & 55 & 3 & 2 & 2 & 1 \\
\hline & $\%$ & 87.2 & 4.8 & 3.2 & 3.2 & 1.6 \\
\hline \multirow{2}{*}{ P2 } & $\mathrm{N}$ & 222 & 11 & 6 & 12 & 2 \\
\hline & $\%$ & 87.8 & 4.3 & 2.4 & 4.7 & 0.8 \\
\hline \multirow{2}{*}{ P3 } & $\mathrm{N}$ & 76 & 6 & 7 & 9 & 10 \\
\hline & $\%$ & 70.3 & 5.6 & 6.5 & 8.3 & 9.3 \\
\hline \multirow{2}{*}{$\geq \mathbf{P 4}$} & $\mathrm{N}$ & 38 & 1 & 5 & 7 & 3 \\
\hline & $\%$ & 70.4 & 1.8 & 9.2 & 13.0 & 5.6 \\
\hline \multirow{2}{*}{ Total } & $\mathrm{N}$ & 410 & 21 & 20 & 30 & 16 \\
\hline & $\%$ & 82.6 & 4.2 & 4.0 & 6.0 & 3.2 \\
\hline
\end{tabular}

$\mathrm{P}$ value $<0.001$

Table 5: Relationship between age at first pregnancy and cytological findings $(n=483)$.

\begin{tabular}{|c|c|c|c|c|c|c|}
\hline \multirow{2}{*}{\multicolumn{2}{|c|}{$\begin{array}{l}\text { Age at first } \\
\text { pregnancy } \\
\text { (in years) }\end{array}$}} & \multicolumn{5}{|c|}{ Cytological findings on Pap smear } \\
\hline & & NILM & Unsatisfactory & ASCUS & LSIL & HSIL \\
\hline \multirow{2}{*}{$\leq \mathbf{2 0}$} & $\mathrm{N}$ & 68 & 7 & 9 & 15 & 14 \\
\hline & $\%$ & 60.1 & 6.2 & 8.0 & 13.3 & 12.4 \\
\hline \multirow[b]{2}{*}{ 21-30 } & $\mathrm{N}$ & 311 & 13 & 10 & 15 & 2 \\
\hline & $\%$ & 88.6 & 3.7 & 2.8 & 4.3 & 0.6 \\
\hline \multirow{2}{*}{$>\mathbf{3 0}$} & $\mathrm{N}$ & 12 & 1 & 1 & 0 & 0 \\
\hline & $\%$ & 85.8 & 7.1 & 7.1 & 0.0 & 0.0 \\
\hline \multirow{2}{*}{ Total } & $\mathrm{N}$ & 391 & 21 & 20 & 30 & 16 \\
\hline & $\%$ & 81.8 & 4.4 & 4.2 & 6.3 & 3.3 \\
\hline
\end{tabular}

$\mathrm{P}$ value $<0.001$

Table 6: Correlation between chief complaints and cervical cytology report

\begin{tabular}{|lllllll|}
\hline Variables & & Unsatisfactory & NILM & ASCUS & LSIL & HSIL \\
\hline \multirow{2}{*}{ Discharge per vaginum } & $\mathrm{N}$ & 4 & 117 & 7 & 9 & 4 \\
\cline { 2 - 7 } & $\%$ & 2.8 & 83.0 & 5.0 & 6.4 & 2.8 \\
\hline \multirow{2}{*}{ Pain abdomen } & $\mathrm{N}$ & 9 & 103 & 1 & 7 & 1 \\
\cline { 2 - 7 } & $\%$ & 7.4 & 85.1 & 0.8 & 5.8 & 0.8 \\
\hline \multirow{2}{*}{ Menstrual abnormality } & $\mathrm{N}$ & 3 & 80 & 6 & 8 & 1 \\
\cline { 2 - 7 } Dysuria & $\%$ & 3.1 & 81.6 & 6.1 & 8.2 & 1.0 \\
\hline \multirow{2}{*}{ Asymptomatic } & $\mathrm{N}$ & 2 & 35 & 1 & 1 & 0 \\
\hline \multirow{2}{*}{ Pruritis } & $\mathrm{N}$ & 0 & 89.7 & 2.6 & 2.6 & 0.0 \\
\hline \multirow{2}{*}{ Postmenopausal bleeding } & $\%$ & 0.0 & 36 & 1 & 0 & 0 \\
\hline \multirow{2}{*}{ Post coital bleeding } & $\mathrm{N}$ & 1 & 97.3 & 2.7 & 0.0 & 0.0 \\
\cline { 2 - 7 } & $\%$ & 2.8 & 28 & 3 & 0 & 4 \\
\hline & $\mathrm{N}$ & 0 & 77.9 & 8.3 & 0.0 & 11.1 \\
\hline
\end{tabular}

$\mathrm{P}$ value $<0.001$ 
Table 7: Correlation between per speculum findings and cytology report $(n=497)$.

\begin{tabular}{|c|c|c|c|c|c|c|}
\hline Variables & & NILM & Unsatisfactory & ASCUS & LSIL & HSIL \\
\hline \multirow{2}{*}{ Normal } & $\mathrm{N}$ & 107 & 9 & 2 & 2 & 1 \\
\hline & $\%$ & 88.4 & 7.4 & 1.7 & 1.7 & 0.8 \\
\hline \multirow{2}{*}{ Hypertrophy } & $\mathrm{N}$ & 101 & 6 & 5 & 11 & 5 \\
\hline & $\%$ & 78.9 & 4.7 & 3.9 & 8.6 & 3.9 \\
\hline \multirow{2}{*}{ Erosion } & $\mathrm{N}$ & 63 & 0 & 4 & 5 & 3 \\
\hline & $\%$ & 84.0 & 0.0 & 5.3 & 6.7 & 4.0 \\
\hline \multirow{2}{*}{ White discharge } & $\mathrm{N}$ & 101 & 2 & 2 & 4 & 0 \\
\hline & $\%$ & 92.7 & 1.8 & 1.8 & 3.7 & 0.0 \\
\hline \multirow{2}{*}{ Unhealthy } & $\mathrm{N}$ & 38 & 4 & 7 & 8 & 7 \\
\hline & $\%$ & 59.4 & 6.3 & 10.9 & 12.5 & 10.9 \\
\hline \multirow{2}{*}{ Total } & $\mathrm{N}$ & 410 & 21 & 20 & 30 & 16 \\
\hline & $\%$ & 82.5 & 4.2 & 4.0 & 6.0 & 3.2 \\
\hline
\end{tabular}

$\mathrm{P}$ value $<0.001$

\section{Per speculum findings}

Amongst the per speculum findings, cervix was normal looking in $121(24.2 \%)$ women. Cervical hypertrophy was most common in $128(25.6 \%)$. Other findings, white discharge per vaginum, erosion of cervix, unhealthy cervix and frank growth were seen in $21.8 \%, 15 \% 12.8 \%$ and $0.6 \%$ respectively. Out of 66 women with positive cytology findings, $22(33.3 \%)$ had unhealthy cervix, 21 $(31.8 \%)$ had hypertrophied cervix followed by cervical erosion in $12(18.2 \%)$ patients, white discharge in 6 $(9.1 \%)$ and normal looking cervix in $5(7.58 \%)$ patients. Out of three women who had frank growth on per speculum examination, 2 patients were found to have squamous cell carcinoma of the cervix belonging to stage IIA2 and stage IIB respectively and 1 patient had adenocarcinoma of cervix which was in stage IB3.Significant correlation was found between the chief complaints and per speculum findings with the cytology and histopathology report $(\mathrm{p}<0.001)$.

\section{DISCUSSION}

Persistent infection with human papilloma virus (HPV) is well established and essential factor for the development of pre invasive lesions of cervix and their progression to invasive malignancy. But there are many other epidemiological risk factors which play an important role in the development and progression of these lesions. Increasing age, low socioeconomic status, low education, early coitarche and early age at first child birth are all interrelated and are main epidemiologic risk factors found in this study for the development of pre invasive and invasive lesions of cervix. Another noteworthy point observed in the study is that symptomatic patients had increased frequency of cytological abnormalities on Pap smear and dysplasia/ cervical carcinoma on histology. The complaints of post coital bleeding and postmenopausal bleeding are strongly associated with epithelial lesions, dysplasia and cervical cancer and thus should not be ignored. It is also noted that the frequency of squamous intraepithelial lesions (SIL) on Pap smear was very high in women with clinical lesions of the cervix $(16.2 \%)$ as compared to the healthy cervix $(4.1 \%)$. Thus it can be stated that simple per speculum examination of patients attending the health centre can help in significantly reducing the burden of carcinoma cervix.

Substantial correlation could not be established between residence, religion, prolonged use of OCPs, occupation, multiple sexual partners and the development of preinvasive and invasive lesions of cervix. Kashyap et al noted correlation between lack of education, not maintaining personal hygeine, early age of marriage, increasing number of husband's sexual partners, history of sexually transmitted diseases and lack of knowledge about screening as risk factors for cervical cancer. ${ }^{17}$ Bhatnagar et al, observed relationship between low level of education, low socioeconomic status, early age of marriage, high parity and complaint of discharge per vaginum. $^{18}$

The study by El-Moselhy et al showed that lowest education level, lowest occupation level, low social class, rural residence, increasing age, young age at marriage, young age at first full term pregnancy, grand multiparity, multiple sexual partners as risk factors for cervical cancer. ${ }^{19}$ In the study conducted by Khalaf et al concluded no correlation between residence, occupation and smoking and the development of preinvasive and invasive lesions of the cervix. ${ }^{20}$ The study by Gupta et al noted that the frequency of cytopathological abnormalities rose with increasing age. Early age at first coitus, increasing parity, complaints of post coital bleeding per vaginum, clinical lesions of cervix on per speculum examination were associated with cervical cancer. $^{21}$

In the study by Mhaske et al noted that age at marriage below 17 years, first childbirth below 20 years and development of cervical cancer. ${ }^{22}$ Mishra et al showed that cervical dysplasia showed a progressive rise with increasing age and parity. ${ }^{23}$ Though the percentage of 
dysplastic smears was found to be high in women married between 21-30 years.

\section{CONCLUSION}

Cervical cancer is a major public health problem especially in the developing countries. Cancer of cervix is a preventable cancer as it is associated with a long preinvasive stage comprising of cervical intraepithelial lesion developing over years. Though persistent infection with Human papilloma virus is essential for the development of the disease, there are other high-risk factors (age, poor education, low socioeconomic status, early age at marriage and high parity) which are significantly associated with the occurrence of the disease. Therefore, our primary and secondary preventive measures must include the women who come under these high risk categories. Spreading awareness about cervical cancer, its prevention by safe sexual practices, availability of different screening methods and motivating women to follow the screening guidelines should be stressed upon. Epithelial cell abnormalities were noted more in patients with abnormal per speculum findings, hence per speculum examination in low resource settings can be used as an effective tool for secondary prevention. High frequency of epithelial cell abnormalities was noted in patients with post coital bleeding and postmenopausal bleeding. Hence mandatory cytological evaluation must be done in such cases. To conclude community-based screening camps should be arranged for high-risk population, law regarding age at marriage should be strictly implemented and family planning services must be made available to all women.

\section{Funding: No funding sources}

Conflict of interest: None declared

Ethical approval: The study was approved by the Institutional Ethics Committee

\section{REFERENCES}

1. Globocan 2018: India Factsheet. India against Cancer; 2018. Available at: http://cancerindia.org.in/globocan-2018-indiafactsheet/. Accessed on 01 April 2020.

2. National Institute of Cancer Prevention \& Research. National Cancer Registry Programme of the Indian Council of Medical Research.Over 17 lakh new cancer cases in India by 2020: ICMR. Available at: https://www.ncdirindia.org/Area_Cancer.aspx. Accessed on 20 April 2020.

3. World Health Organisation. International agency for research on cancer. Press release 5th December 2019 New study provides baseline to measure impact of cervical cancer elimination objectives

4. HPV Information Centre - Human papilloma virus and related disease, summary report 17 June 2019.Available at: www.hpvcentre.net. Accessed on 20 April 2020.
5. Bray F, Ferlay j, Soerjomataram I, siegelRl, Torre LA, Jemal A. Global cancer statistics 2018: GLOBOCON estimates odf incidence and mortality worldwide for 36 cancers in 185 countrie. CA Cancer J Clin. 2018;68:394-424.

6. American Cancer Society. Key Statistics for Cervical Cancer.Last Revised: January 8, 2020. Available at https://www.cancer.org/cancer/cervicalcancer/about/ key-statistics.html. Accessed on 20 April 2020.

7. Arbyn M, Weiderpass E, Bruni L, de Sanjosé S, Saraiya M, Ferlay J, Bray F. Estimates of incidence and mortality of cervical cancer in 2018: a worldwide analysis. Lancet Glob Heal. 2020;8(2):e191-203.

8. Papillomaviruses H. IARC monographs on the evaluation of carcinogenic risks to humans. Lyon, France: IARC. 2011. Available at: https://monographs.iarc.fr/wpcontent/uploads/2018/0 6/mono90.pdf. Accessed on 20 April 2020.

9. Sreedevi A, Javed R, Dinesh A. Epidemiology of cervical cancer with special focus on India. Int $\mathbf{J}$ Womens Heal. 2015;7:405-14.

10. Mamulwar M, Godbole S, Bembalkar S, Kamble P, Dulhani N, Yadav R, et al. Differing HIV vulnerability among female sex workers in a high HIV burden Indian state. PLoS One. 2018;13(2):e0192130.

11. Bosch FX, Lorincz A, Muñoz N, Meijer CJ, Shah $\mathrm{KV}$. The causal relation between human papillomavirus and cervical cancer. J Clin Pathol. 2002;55(4):244-65.

12. Louie KS, De Sanjose S, Diaz M, Castellsague X, Herrero R, Meijer CJ, Shah K, Franceschi S, Muñoz $\mathrm{N}$, Bosch FX. Early age at first sexual intercourse and early pregnancy are risk factors for cervical cancer in developing countries. Brit $\mathrm{J}$ Canc. 2009;100(7):1191-7.

13. Ursin G, Peters RK, Monroe K, Pike MC, Henderson BE. Oral contraceptive use and adenocarcinoma of cervix. Lancet. 1994;344(8934):1390-4.

14. Schiffman M. Cancer Epidemiology and Prevention. In: Schottenfeld D, FraumeniJr JF, editors, 3rd Edn. Oxford University Press; 2006.

15. McGraw SL, Ferrante JM. Update on prevention and screening of cervical cancer. World J Clinic Oncol. 2014;5(4):744.

16. Fahey MT, Irwig L, Macaskill P. Meta-analysis of Pap test accuracy. Am J Epidemiol. 1995;141(7):680-9.

17. Kashyap N, Krishnan N, Kaur S, Ghai S. Risk factors of cervical Cancer: a case-control study. Asia-Pacific J Oncol Nurs. 2019;6(3):308.

18. Bhatnagar K, Baghel K. Epidemiology of patients with bad cervix attending gynaecology OPD of a tertiary care centre in western Uttar Pradesh, India. Int J Reprod Contracept Obstet Gynecol. 2017;6:791-6.

19. El-Moselhy EA, Borg HM, Atlam SA. Cervical Cancer: sociodemographic and clinical risk factors 
among adult Egyptian females. Adv Oncol Res Treat. 2016;1(1):106.

20. Khalaf MK, Rasheed FA, Hussain SA. Association between early marriage and other sociomedical characteristics with the cervical pap smear results in Iraqi women. Advan Sex Medic. 2015;5(04):73.

21. Gupta K, Malik NP, Sharma VK, Verma N, Gupta A. Prevalence of cervical dysplasia in western Uttar Pradesh. J Cytol Acad Cytolog. 2013;30 (4):257.

22. Mhaske M, Jawadekar SJ, Saundale SG. Study of association of some risk factors \& cervical dysplasia/cancer among rural women. Nat $\mathbf{J}$ Comm Med. 2011;2(2):209-12.

23. Misra JS, Srivastava S, Singh U, Srivastava AN. Risk-factors and strategies for control of carcinoma cervix in India: Hospital based cytological screening experience of 35 years. Ind J Canc. 2009;46(2):155.

Cite this article as: Bhardwaj G, Kaur A, Bagga PK. Epidemiology of pre invasive and invasive lesions of the cervix at tertiary health centre in Punjab. Int $\mathbf{J}$ Reprod Contracept Obstet Gynecol 2021;10:1393400. 